\title{
Using the Multiple Assessment Method to Improve the Teaching Quality of University non-test based Course
}

\author{
YAO Chifu \\ Department of Computer and Information, Shanghai Second Polytechnic University, Pudong Shanghai \\ 201209, China \\ yao_chifu@163.com
}

Keywords: multiple assessment method; non-test based course; performance in class; creativity; teaching quality;

Abstract. Based on the analysis of the non-test based course in the teaching method and effect still has many relatively problems, analyzing its characteristics and importance, especially what the test course cannot be replaced with. Next, how to use the multiple assessment method for teaching of the non-test based course, including how to formulate the scoring rules, how to conduct classroom design, final assessment method is introduced. Finally, the application prospect of multiple assessment method in the non-test based course are analyzed and expected.

\section{Introduction}

The current examination methods of non-test based course make students lack the pressure and motivation of study. There are three solutions for schools, teachers and students. The school should improve the current assessment mechanism. At the same time, teachers should take the initiative to study the methods of examining the course assessment, focusing on process assessment. Students change utilitarian heart and enhance self-discipline consciousness[1]. Due to the scores of test subjects of various grades of subjectivity, university ranking, evaluation and examination results are not relevant to course, so in the minds of college students they will naturally place the non-test based course in a 'mixed' position, so no motivation to learn. Some students said, "not only do not go to class, even the homework is also dealt with"[2].

\section{The importance of non-test based course}

The non-test based course is that students are on time in class time, but the school don't organize the examinations, the final scores is mainly to the teachers, the scores accounted for about $60 \%$, the rest of the final, when the teacher himself organize the examinations or submit a paper, accounting for about $40 \%$. The non-test based course, for a period of time, we all pay attention to inadequately, class discipline relatively loose compared with the test course , basically this courses pay more attention to attendance, the final assessment scores of teachers are also optional.

The test courses at final will be organized a unified examination, usually need to study hard though students are not easy to pass through this courses. For non-test course, by the end of term the school will not organize the examination, teachers decide the way of examination, such as writing papers, doing PPT, writing experience, and so on. Usually though you hardly take part in lessons, you can still pass this course by studying well through reading lots of related material. Usually, it is very like the elective course, and examination pass rate is relatively high.

Test courses are usually major courses, such as advanced mathematics, general physics, foreign language and other public basic courses, major courses in junior middle school and major courses in junior college. The test course usually arranges 4-5 courses each semester, requiring examination papers, and the scores are registered with the hundred mark system.

Non-test based courses usually are auxiliary course or elective courses, such as general college PE, some ideological and political courses, and some public elective courses for developing knowledge. There are also some specialized elective courses with fewer class hours. In addition to the 
examination paper, examination forms can also be used in social investigation, learning experience and other forms, and the examination results are generally evaluated by grading system.

The non-test based course can train students' ability to look outside materials, stimulate the power of independent study, and develop the horizons of various aspects of learning, instead of memorizing the materials, ignoring the reference books, and trying to solve the test problems[3]. This results in the test course to cultivate practical and innovative abilities of students in the aspects of phase lacking, which also makes it an important reason for colleges not to be able to list all the teaching subjects in the courses of development.

To non-test course, test course is paid more attention by schools, teachers and students. Through filtering, which courses are test courses or non-test based courses are decided. To a same course, whether it is test course or non-test based course, for different major, it is different. Test course means this course is more important and need to pay more attention to. Non-test based course means this course as long as the students understand some relevant knowledge.

\section{The main problems of the non-test based course}

In the University's teaching program, there is a certain proportion of test subjects required in the course arrangement, so as to guarantee the quality of teaching without giving too much discount. The implication is that the non-test based course is not as strict as the test course and the quality of the test course. In my view, it is not necessarily, according to my experience of teaching experience, I have taken the IPv6 technology and the premises distribution system, and the teaching effect is also very good, and the quality of teaching is also very high. This can be corroborated by student's class performance, final grades, employment after graduation, and interviews with graduates.

General non-test based course evaluation methods are usually at ordinary times, usual work, plus the end of the big homework or class with class assessment. Because the final assessment period or lax invigilation, which usually made students who are not hard-working or learning not well are easy to muddle through. This makes it easy for people to think that the non-test based course is easy to muddle through, or that the non-test based course is unimportant, while others think that the non-test based course is difficult to reflect the students' true mastery level.

Why is everyone on the non-test based course easily lead to the wrong understanding and why the non-test based course is easy to be underestimated? The reason is mainly because the traditional non-test based course assessment methods are still existing more disadvantages, causing the students do not pay attention to the non-test based class, the employer also underestimate grades based on non-test based course, leading to the position of non-test based course is lower than the test course. Based on the above analysis, the non-test based courses same as the test courses are essential in the professional training program. In the growth of professional study is as important as the test course. Therefore, we must study some feasible teaching methods and means to improve the effects of the non-test based course, to solve the universal poor non-test based course of teaching quality and teaching effect, the phenomenon caused by contempt. After years of practice, the multiple assessment method has been proved an effective and good teaching method, and it is an effective means to improve the teaching effect and teaching quality of the non-test based course. The following is called the multi-assessment method.

\section{4 the multiple assessment method in non-test based course}

In the course of teaching for many years, I have summed up a method of evaluating the non-test based course by multi-assessment method. It has produced very good teaching effect in the course of teaching, and now introduces several main methods of it.

\subsection{Asking, answering and marking during class}


A non-test based course usually has a certain proportion of theoretical class hours. As a non-test based course generally does not have the theoretical content of the closed volume examination, so students generally believe that the theoretical content is not grasped well, it does not matter. Therefore, if you do not put the theory class very good living, don't ask questions and scoring more in theory class, it will not guarantee to make the students learn the theoretical knowledge, but also because there is no pressure and relax on the theory of knowledge. Therefore, it is also a very important link to have good and good theoretical courses.

\subsection{The quality and time of the competition in the experimental class}

In the process of making the network crystal head, I adopted the two index comprehensive evaluation method of fast time and high quality, and the teaching effect and routine grading experiment were compared as followed.

Table 1 comparison of experimental data of RJ45 connection making

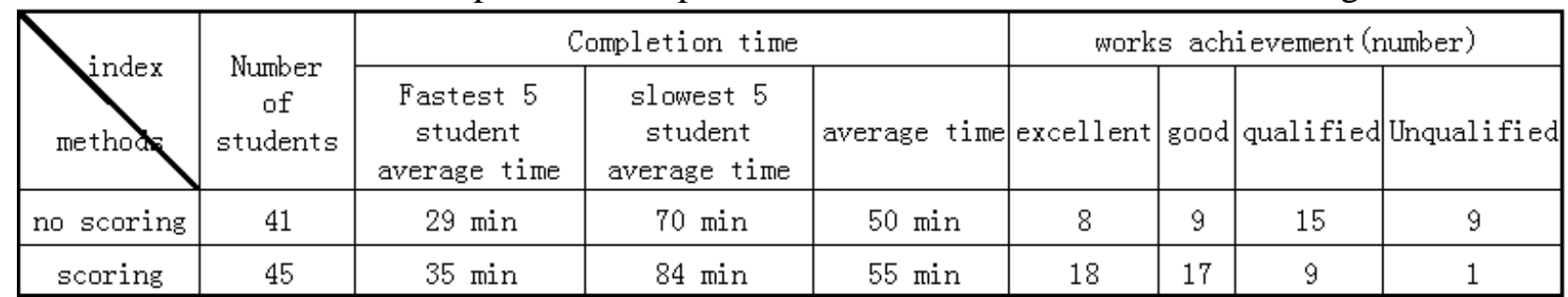

From the data of the table 1, you can see when just to judge the RJ45 connection whether is well made, but do not mark the score, the average time of the fastest 5 students are usually shorter, and the slowest time is almost the same. Fast because not very concerned about the quality of good or bad, so fast. And the slowest 5, why is faster than the score assessment, they maybe have seen other students completed the experiment to go, and they also handed over the work hastily and went. But the teaching quality resulting from the two methods are not the same, the later method of grade ranks two high and two low, it can be seen that the evaluation effect is obvious: outstanding number and good number increased, and the qualified and unqualified scores fell.

In the static routing configuration experiment of IPv6 technology, also made a similar contrast experiment, but the "works" of the score assessment is the experimental report of electronic version and configuration of the network, all can Ping.

Table 2 Comparison of experimental completion time

\begin{tabular}{|c|c|c|c|c|c|c|c|c|}
\hline \multirow{2}{*}{ index } & \multirow{2}{*}{$\begin{array}{l}\text { Number } \\
\text { of } \\
\text { students }\end{array}$} & \multicolumn{3}{|c|}{ Completion time (total 8 groups) } & \multicolumn{4}{|c|}{ Member participation } \\
\hline & & $\begin{array}{c}\text { finished } \\
\text { in } 40 \text { mins }\end{array}$ & $\begin{array}{c}\text { finished } \\
\text { in } 60 \text { mins }\end{array}$ & $\begin{array}{c}\text { finished } \\
\text { in } 80 \text { mins }\end{array}$ & $\begin{array}{c}\text { Extremely } \\
\text { earnest }\end{array}$ & earnest & onlooking & indifferent \\
\hline no scoring & 41 & 0 groups & 2 groups & 6 groups & 8 persons & 19 persons & 12 persons & 2 persons \\
\hline scoring & 45 & 1 groups & 4 groups & 3 groups & 16 persons & 23 persons & 5 persons & 1 persons \\
\hline
\end{tabular}

From the above two class examples and analysis, we know that the scoring evaluation of network engineering experiment class effect has been significantly improved.

\section{3 the final assessment of the work is a comprehensive design (Thesis)}

The non-test based course should not only grasp the knowledge points of the students, but also should examine students' comprehensive application ability of the course design and implementation ability, which is also the place where the non-test based course is more able to train students' practical abilities than the test course. Therefore, in the final examination of computer examination courses, students are required to submit a comprehensive design with a certain level of complexity, including certain technical requirements, using certain knowledge and skills to complete the project description, including project description, demand analysis, project design, technical proposal and implementation procedures, debugging and acceptance process documentation, code chart, etc. These 
contents are difficult to assess in the test course, and this is also the advantage of the non-test based course. It makes the test course unable to replace itself.

For a non-test based course, not only to examination whether students have understood the skills and have grasped each knowledge point, but also the assessment of their comprehensive understanding, in the course of the comprehensive ability of design, so it is recommended to have the last major operations, comprehensive design or thesis, and referred to large homework in the context. A big job's content is very important, the students can't just write an article related to the course, otherwise, the big work of these students is likely because the target is not clear and uneven, many students through the" bully ", completed the assessment of the course at the end of period. In addition, if you do not usually score points, this course will give students an impression - the bully can pass the non-test based course.

\section{4 the final assessment process requires speech and defense}

In order to verify that large assignments are done by students themselves and the depth and breadth of their knowledge, they should be asked to come up on stage to explain their designs and to answer questions on the spot. This practice puts a lot of pressure on the students, because the short board of Chinese College Students - poor speech, is the biggest revelation. The contents are not familiar with, or rely on others to assist, especially the copying process works, it will make them sleepless at nights, and revealed the secret in front of the questions of classmates and teachers

For application-oriented, let the students in the audience, deepen their understanding of the project design plan and technical route of understanding, so that they learn how to convince users to understand what advantages and benefits, effect, plan is very important, but also to let them cost a qualified project management or project manager quality. Only when students have a thorough understanding and grasp of the background, requirements, design basis and implementation process of the project, can they give a good speech on stage, and be able to do the spot defense more freely. This will ensure that the assessment of the non-test based courses, although not closed volumes, but there are also the effect of fairness of closed volumes examination assessment.

\section{5 the scoring items and score percentage should be scientific and reasonable}

But in all kinds of experiment content, how to design the examination method and check what index is very important. If properly designed, it can not only complete the content specified in the teaching plan and achieve the intended goal, but also greatly stimulate the enthusiasm of the students. But if the design is not appropriate, students may finish very quickly, but is do not meet the teaching effect we have set, and ultimately let the students lose their motivation. Then, how should we design assessment methods and assessment indexs?

The laboratory is the base for training creative talents. A talent with creative ability, comprehensive quality , we can't imagine that he just can do this by reading, relying on knowledge accumulation, must practice and do experiment more[4]. Therefore, the non-test based classes of university should make more use of laboratory, the teaching and training base, to practice teaching, scene teaching, also can make non-test courses lively and vivid, and let the students develop professional horizons and cultivate the practical ability to solve problems. While these courses in the teaching process using each-time evaluation method, not only can inspire students put into it very seriously each time, but also more objectively reflect students' mastery of knowledge and skills, and ultimately enable students to score high and in corresponding with high ability, to form a benign evaluation mechanism to stimulate the enthusiasm of students, let the students have other students' real worship, the effect of role is also significantly high than assessment methods and skills. 


\section{5. how to formulate the scientific proportion of examination results?}

Because there is no uniform evaluation mode, evaluation has great randomness. As a computer professional course, examine the course assessment methods usually have the final the following several ways, students write a thesis; a plan of design network program or software solutions; write a set of software, plus the usual form of classroom questioning as a basis for evaluation and assessment methods are based on the above several subjective evaluation are based on teachers[5].

In curriculum evaluation, we adopt the combination of process evaluation and summative evaluation, qualitative evaluation and quantitative evaluation, and adopt flexible and diverse evaluation methods[6]. Results can be as follows: attendance $10 \%$, homework $20 \%$, usually performance $30 \%$, end of small design (Thesis) 40\%. This result can not only reflect the proportion of students attendance, because attendance is diligent, work and usual performance can not only reflect the performance of intelligence, ability, but also can reflect the degree of seriousness and diligence. The completion of the design and the quality of the defense at the end of the semester can reflect the students' comprehensive understanding and comprehensive application ability of the course knowledge.

Usually 30\% of the performance, have good design, cannot obscure, or even score students by feeling at the end of the semester, but the assessment index should be specific, quantified. For example, how many questions are asked and answered in class? How many times do you finish the experiment and how is the quality? Problems finding and self-creation experience method plus. This kind of assessment, guide students to listen carefully in class, and actively answer questions, experiment attentively, good at observing and summing up experience, making the examination course teaching process is very energetic.

\section{Comments on the class design of assessment method}

The non-test based course aims to improve the quality of students, let the students find pleasure at the same time of learning, study full of interest, therefore, to the non-test based course teachers must not let a person to sing "one-man show", but should reflect the students' dominant position, let the students participate in [7].

To fully play a guiding role in the case, the purpose is to enable students to participate in the direct exchange of learning, the former class will be the next class will involve the case arranged in advance to the students, or allow students to collect relevant cases, their group prepared in the classroom so that students express their views and opinions of cases[8]. The idea and application scenarios, on issues in the case of the implementation of technology, test results and conclusion, guiding students to use computer interlocking system and engineering thinking to solve the problem, analyses the problem with information system thinking. Role playing method, refers to the process in the discussion of case study, the students will be divided into several groups, as the construction team, different subsystem implementers, the construction process simulation of large electricity engineering subcontract and the contractor in the construction management process. This method can help students to reveal the complexity of construction management and the characteristics of concurrent construction management. At the same time, the same project case can be divided into two parts: subcontracting method and all construction methods, so as to deepen the students' understanding of the advantages and disadvantages of the subcontracting of large projects. The field of interpretation, refers to the formation of the teaching practice of cooperation between colleges and enterprises of computer professional, leading the students to visit the project site, without affecting the project construction situation, letting the students to feel the atmosphere of the scene and the project construction site. The defect of this teaching method is the high cost of travel, teaching assessment is difficult, some of the projects by the number of students scale limit, to gradually open up, and in the light of its general trend, pay attention to retain the photos and videos and written material archives ${ }^{7}$ and so on 


\section{Effect and Outlook}

After nearly four terms of network engineering students "comprehensive wiring system", "IPv6 technology", "computer network", "practice and communication network application system integrated design practice" of several professional test classes the statistical analysis of the results obtained are as follows, distribution of the number of students using credit points and weighted method:

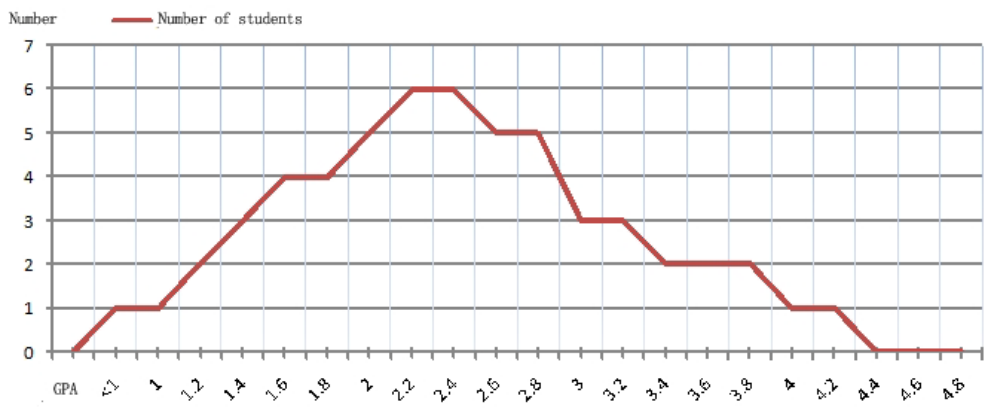

Fig. 1 distribution points using the traditional teaching method

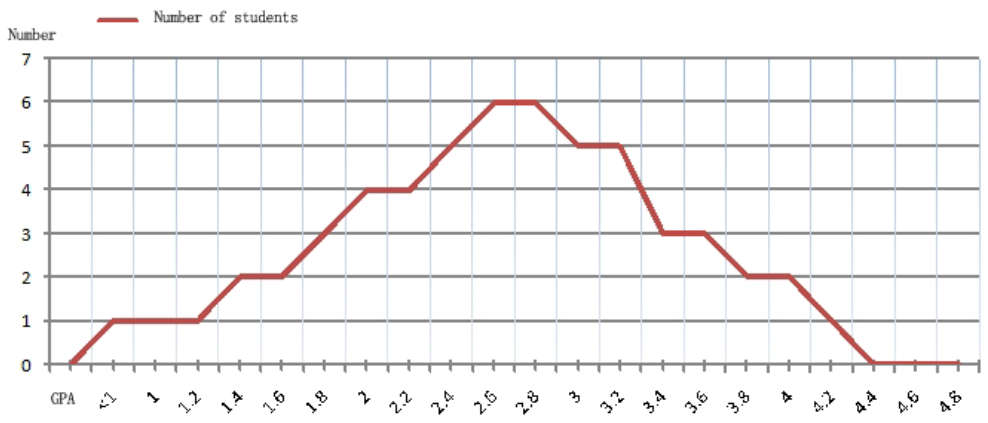

Fig. 2 distribution points when using multiple assessment method

Comparing Figure Fig.1 and Figure Fig.2, found that the use of "in front of many times before the examination method of two terms, from the test score distribution, low grades of segments of the number is relatively more, also a little lower GPA. And the two terms behind using "multiple assessment method" in the future, CHINT scores distribution curve of the highest point to the right, GPA has increased, especially rarely below 2.0, which is conducive to their bachelor's degree. Through in-depth analysis, the student survey finding that students of "repeated examination" is still very positive, they think "multiple assessment method has the following advantages:

(1). assessment contents and methods are of open and transparent;

(2). which results from the beginning to the end of the course has been included, not because of a poor play and a decision class;

(3). teachers pay more attention to class in the process of observation assessment, and improve the participation of students and also make them become attentive;

(4). comprehensive design and defense solutions are able to exercise their professional comprehensive ability.

\section{Conclusion}

how to innovative teaching and evaluation of test methods, how to improve the enthusiasm of students, how to stimulate students' class participation and competition, is to improve the learning effect of test course, especially an urgent issue to examine the current course of computer specialty. Using test course teachers have greater flexibility and evaluation methods of space innovation teaching mode, make up the current situation that heavy theory and the students of college in our country is good at memorizing, but lack of practical ability and innovation ability. Thus, not only the examination class is considered as a supporting role, "easy to muddle through", but also a kind of curriculum assessment type which mainly takes on innovative ability training and enables students to develop in an all-round way. 


\section{Acknowledgements}

This work is supported by the Key Disciplines of Computer Science and Technology of Shanghai Polytechnic University (No. XXKZD1604), the experimental major of practical undergraduate Shanghai(A30DB172202-4).

\section{References}

[1] X. Gao, in: Reform and Innovation of Examination Methods, Read and Write Periodical, Vol. 12 no.6, p. 36, June 2015.

[2] Y. Wu, Y. Yang, in: Teaching Analysis of University Examination Course, University Education, p.44-46, November 2015.

[3,8] X. Wang, in: Taking Arbitration Law as An Example to Discuss the Reform of Examination Mode, University Education, p.177-178,December 2016.

[4] C. Yao, X. Chen, in: Design and Implementation of Remote Network Laboratory Based on SNMP and Web, Research and Exploration in Laboratory, p.260-263, October 2016.

[5] Y. Pei, Q. Han, M. You, Discussion on Quantitative Examination Standard in Computer Examination Course, Higher Education, p.127-128,August 2015.

[6] Y. Wang, E. Zhao, in: Inquiry Into the Teaching Means of Water Pollution Control Engineering in Environmental Engineering, Shandong Chemical Industry, p.180-181, p.183, August 2016

[7] Y. Li, in: Reform and Exploration of Teaching Methods and Achievement Evaluation in Examination Course, Science \& Technology Information , p.243, December 2012 